\title{
Усиление частотно-модулированных волновых пакетов в среде с бегущей волной показателя преломления
}

И.О. Золотовский", А.С. Кадочкин, В.А. Лапин, Д.Г. Санников, М.С. Явтушенко

Ульяновский государственный университет, 432970, Ульяновск, Россия

*E-mail: rafzol.14@mail.ru

DOI: 10.31868/RFL2020.91-93

При распространении светового импульса по световоду, в котором сформирована бегущая волна показателя преломления (БВПП), могут наблюдаться эффекты, не имеющие места в световодах со стационарными параметрами [1], такие как изменение поляризации и смещение несущей частоты, формирование солитоноподобных волновых пакетов, развитие индуцированной модуляционной неустойчивости $(\mathrm{MH})$ и генерация пикосекундных импульсов. В настоящей работе предложена методика усиления и модуляции импульсов в активной среде с реализуемой БВПП.

Пусть в световоде возбуждена БВПП вида [2]:

$$
n(t, z)=n_{0}(1-m \cos (\Omega t-q z))
$$

и попутно с ней распространяется ЧМ-импульс с начальными условиями:

$$
A(t, z=0)=A_{0} \exp \left(-\left(\tau_{0}^{-2} / 2-i \alpha_{0}\right) t^{2}\right),
$$

где $n$ - показатель преломления (ПП), $\Omega$ - частота модуляции ПП, $q=2 \pi / \Lambda$ волновое число, $\Lambda$ - период пространственной неоднородности ПП, $V_{m}=\Omega / q-$ фазовая скорость перемещения БВПП, $m=\Delta n / n_{0}$ - глубина модуляции ПП, $\Delta n-$ амплитуда изменения ПП, $A_{0}, \tau_{0}, \alpha_{0}$ - начальные амплитуда, длительность, скорость ЧМ (чирп) гауссова импульса. Динамика импульса описывается соотношением [3]:

$$
\frac{\partial A}{\partial z}-i \frac{d_{2}}{2} \frac{\partial^{2} A}{\partial \tau^{2}}+\frac{d_{3}}{6} \frac{\partial^{3} A}{\partial \tau^{3}}+i R\left(|A|^{2}-\tau_{R} \frac{\partial|A|^{2}}{\partial \tau}\right) A=i \beta m \cos [\Omega(\tau-\delta \tau)] A+g A
$$

Здесь $v_{g}=(\partial \omega / \partial \beta)_{\omega_{0}}-$ групповая скорость волнового пакета; $d_{n}=\left(\partial^{n} \beta / \partial \omega^{n}\right)_{\omega_{0}}-$ дисперсионные параметры высших порядков, $\beta=n_{0} \omega_{0} / c ; R-$ коэффициент кубической (керровской) нелинейности; величина $\tau_{R}$ - параметр, характеризующий эффект вынужденного комбинационного саморассеяния [3] среды; $\tau=t-z / v_{g}$ - время в бегущей системе координат, связанной с импульсом; $g(\omega)=g_{0}\left[1+\left(\omega-\omega_{r e s}\right)^{2} / \Delta \omega_{L}^{2}\right]^{-1}-$ коэффициент усиления в активной среде с БВПП, где $\omega_{r e s}-$ резонансная частота линии усиления, $\Delta \omega_{L}-$ ширина линии усиления; величина $\tau-\delta \tau=\tau-\left(v_{m}^{-1}-v_{g}^{-1}\right) z \quad$ характеризует рассогласование групповой скорости волнового пакета и фазовой скорости БВПП.

При условии малого рассогласования БВПП и волнового пакета (т.е. $\delta \tau \leq 10^{-11} c$, при $|\Omega| \tau_{u}<<1$, где $\tau_{u}$ - длительность импульса) показано, что возможна сверхбыстрая модуляция импульса при сохраняющейся линейности 
ЧМ и большой ширине спектра. Это, в свою очередь, делает возможным дальнейшее сжатие импульса. Так, при положительном значении чирпа сжатие можно осуществить на дифракционных решетках. Если же у импульса сформировался отрицательный чирп, то для его дальнейшего сжатия может быть использован обычный световод с нормальной материальной дисперсией.

На рис.1 представлена динамика огибающей ЧМ-импульса (рис. 1а) и его спектра (рис.1б) в активном световоде с различными значениями нелинейности $R=10^{-7} ; 10^{-5} ; 10^{-3}(B m \cdot M)^{-1}$ (кривые $1-3$ соответственно).
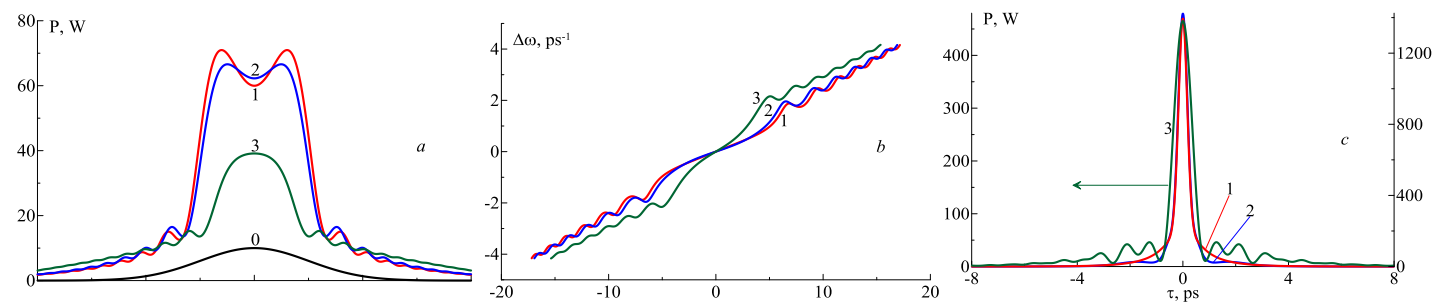

Рис. 1. Начальные параметры импульса: длительность $\tau_{0}=10^{-11}$ с, чирп $\alpha_{0}=0$, пиковая мощность $P_{0}=10$ Вт. Параметры среды с БВПП следующие: частота БВПП $\Omega=10^{9} c^{-1}$; глубина модуляции ПП $\Delta n=10^{-4}$; волновое число $\beta=10^{7} \mathcal{M}^{-1}$; нормальная дисперсия второго порядка $d_{2}=10^{-26} c^{2} / \mathcal{M}$; оптическая длина пути импульса в световоде $L=500 \mathrm{M}$. Параметры линии усиления среды: $g_{0} \approx 10^{-2} \mathcal{M}^{-1}, \Delta \omega_{L}=10^{11} \mathrm{c}^{-1}$.

Как видно из рис. 1б, импульс приобретает практически линейный чирп, значительно уширяется, а его пиковая мощность на выходе из световода с БВПП выросла в 4 (кривые 1,2) и 6 (кривая 3) раз. Пропуская затем такой импульс через диспергирующий элемент (в нашем случае через дифракционную решетку с дисперсионным параметром $D_{\text {eff }}=10^{-24} c^{2} / м$ [3], см. рис.2), можно получить его сильную компрессию (рис.1с), причем его пиковая мощность возрастает более чем на порядок. Из рисунка 1 видно, что широкополосный ВП с шириной спектра $\Delta \omega>10^{12} c^{-1}$ может эффективно (т.е. с сохранением формы) усиливаться в среде со значительно меньшей шириной линии усиления $\left(\Delta \omega_{L}=10^{11} \mathrm{c}^{-1}\right)$.

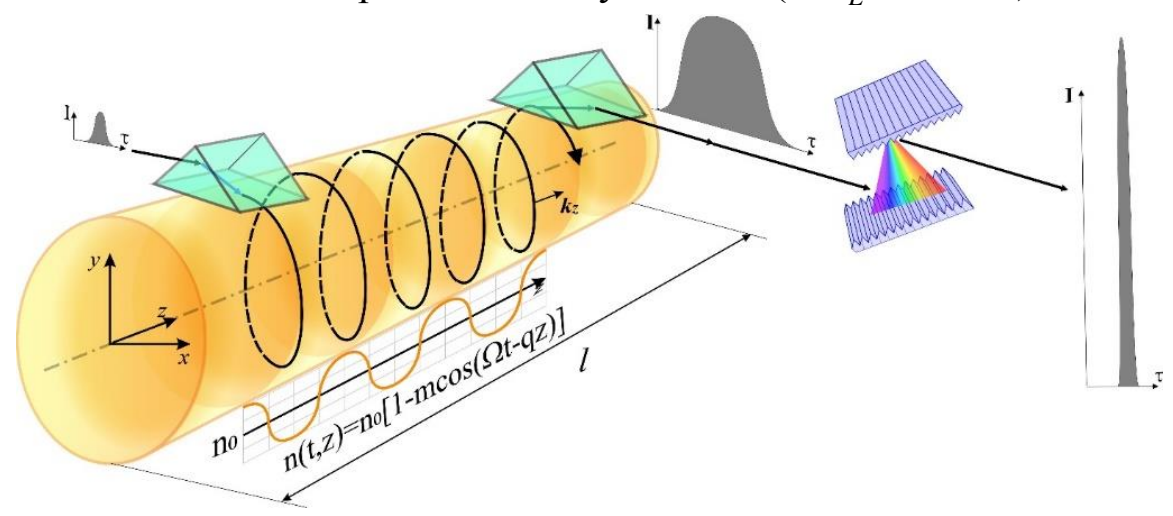

Рис. 2. Схема получения усиленного ЧМ-импульса в световоде с БВПП и его последующая компрессия на дифракционных решетках.

Практическую реализацию усиления импульса можно осуществить в световоде за счет взаимодействия БВПП и поверхностной волны типа моды шепчущей галереи (МШГ). В этом случае волновые пакеты распространяются 
вдоль поверхности кварцевого световода-цилиндра по спирали с постоянным шагом (рис. 2).

Работа выполнена при поддержке гранта РНФ 19-72-10037.

\section{Литература}

[1] Торчигин В.П. Квант. электроника, 22, 509 (1995)

[2] Сычугов В.А., Магдич Л. Н., Торчигин В.П., Квант. электроника, 31, 1089 (2001)

[3] Agrawal G. Nonlinear fiber optics (Springer, fourth edition, 2007) 